\title{
Perceived Family Cohesion Moderates Environmental Influences on Prosocial Behavior in Nigerian Adolescent Twins
}

\author{
Yoon-Mi Hur, ${ }^{1}$ Jeanette Taylor, ${ }^{2}$ Hoe-Uk Jeong, ${ }^{1}$ Min-Seo Park, ${ }^{3}$ and Brett C. Haberstick ${ }^{4}$ \\ ${ }^{1}$ Department of Education, Mokpo National University, Jeonnam, South Korea \\ ${ }^{2}$ Department of Psychology, Florida State University, Tallahassee, FL, USA \\ ${ }^{3}$ Department of Social Welfare, Mokpo National University, Jeonnam, South Korea \\ ${ }^{4}$ Institute for Behavior Genetics, University of Colorado, Boulder, CO, USA
}

\begin{abstract}
Research shows that perceived family cohesion is positively related to prosocial behavior in adolescents. In this study, we investigated heritability of prosocial behavior (PB) and perceived family cohesion (FC) among Nigerian twins attending public schools in Lagos State, Nigeria (mean age $=14.7$ years, $S D=1.7$ years), and explored the issue of whether children's perception of cohesive family environment moderated genetic and environmental influences on (PB). The PB scale of the Strengths and Difficulties Questionnaire and the FC scale of the Family Adaptability and Cohesion Evaluation Scale III were completed by 2,376 twins (241 monozygotic (MZ) male, $354 \mathrm{MZ}$ female, 440 dizygotic (DZ) male, $553 \mathrm{DZ}$ female, and 788 opposite-sex DZ twins). A general sex-limitation and the bivariate genotype by environment interaction $(G \times E)$ models were applied to the data. The general sex-limitation model showed no significant sex differences, indicating that additive genetic and non-shared environmental influences were, $38 \%(95 \% \mathrm{Cl}=31,46)$ and $62 \%(95 \% \mathrm{Cl}=$ $54,69)$ for $\mathrm{PB}$ and $33 \%(95 \% \mathrm{Cl}=24,40)$ and $67 \%(95 \% \mathrm{Cl}=60,76)$ for $\mathrm{FC}$ in both sexes. These estimates were similar to those found in Western and Asian twin studies to date. The correlation between PB and FC was 0.36 . The best-fitting bivariate $\mathrm{G} \times \mathrm{E}$ model indicated that $\mathrm{FC}$ significantly moderated non-shared environmental influence unique to $\mathrm{PB}$ ( $\mathrm{E} \times \mathrm{E}$ interaction). Specifically, non-shared environmental contributions to PB were highest when FC was lowest, and decreased as the levels of FC increased. However, genetic variances in PB were stable across all levels of FC. These findings suggest that FC reduces individual differences in $\mathrm{PB}$ by changing non-shared environmental experiences rather than genetic factors in PB.
\end{abstract}

Keywords: prosocial behavior, family cohesion, twins, gene $x$ environment interaction, environment $x$ environment interaction

Prosocial behavior (PB) is an integral part of human social relationships, involving a variety of positive behaviors including sharing, donating, providing emotional support, helping, and volunteering to benefit others (Eisenberg et al., 2006). PB emerges early in childhood (Brownell, 2013) and demonstrates stability from childhood into adolescence (Eisenberg et al., 1999). It has been reported that adolescent $\mathrm{PB}$ serves as a protective function against association with deviant peers (Carlo et al., 2014), and is related to positive peer interactions (Eisenberg \& Fabes, 1998). Therefore, investigations of the etiology of $\mathrm{PB}$ can provide critical insights into the development of this important human trait.

Twin studies have found that about $30-50 \%$ of the variance in $\mathrm{PB}$ in children and adolescents is due to genetic influences, with the remaining variance being attributable to non-shared environmental influences and measurement error (DiLalla et al., 2015; Gregory et al., 2009; Hur, 2007; Hur \& Rushton, 2007; Scourfield et al., 2004). While twin studies converge on the findings that shared environmental influences on PB are negligible, nuclear family studies have shown that family cohesion (FC) is an important environmental feature associated with the development of PB (Kerr et al., 2003; Sijtsema et al., 2013). FC refers to the emotional bonding, support, and connectedness that family members

RECEIVED 28 February 2017; ACCEPTED 1 March 2017. First published online 28 March 2017.

ADDRESS FOR CORRESPONDENCE: Yoon-Mi Hur, Department of Education, Mokpo National University, Jeonnam, South Korea. E-mail: ymhur@mokpo.ac.kr 
have toward one another (Olson \& Gorall, 2003). Past behavior genetic research has convincingly indicated significant genetic effects on family environment, including perceived FC. For example, in a systematic review of genetic influences on measures of the family environment, Kendler and Baker (2007) found a weighted average heritability estimate for FC to be $24 \%$. In addition, they concluded that genetic effects found for family environment were not solely the result of subjective perception but reflected real environmental experiences because objective measures of family environment also yielded significant genetic influences, although the magnitudes of heritability were somewhat smaller in objective than in self-reported measures of family environment. Behavior geneticists have traditionally divided environmental influences into two sources: shared (i.e., experiences that family members share and making family members similar) and non-shared (i.e., experiences unique to each individual in the family and making family members different) influences. Twin studies of family environment to date have documented that the non-genetic variance found for FC was explained predominantly by non-shared rather than shared environmental influences.

The findings from twin studies of $\mathrm{PB}$ and FC suggest that the etiology of the relationship between $\mathrm{FC}$ and $\mathrm{PB}$ may need to be understood in the framework of geneby-environment $(\mathrm{G} \times \mathrm{E})$ interaction and gene-environment (GE) correlation using a genetically informative design. $\mathrm{G} \times \mathrm{E}$ refers to a situation where the effect of genetic influences varies depending on environmental conditions, and vice versa (Plomin et al., 1977). In the present study, using the bivariate $\mathrm{G} \times \mathrm{E}$ model (Purcell, 2002; van der Sluis et al., 2012) and incorporating FC as an environmental moderator, we aimed to explore how FC moderates genetic and environmental influences on PB. Specifically, we compared the magnitudes of genetic and environmental contributions to the phenotypic variance of $\mathrm{PB}$ across different levels of FC. If genetic effects on $\mathrm{PB}$ vary as a function of FC, then this would indicate the presence of $\mathrm{G} \times \mathrm{E}$. The bivariate $\mathrm{G} \times \mathrm{E}$ model can provide evidence for the existence of $\mathrm{E} \times \mathrm{E}$ interaction as well; if the magnitudes of environmental influences on PB differ across various levels of FC, this would suggest the presence of $\mathrm{E} \times \mathrm{E}$ in the relationship between $\mathrm{PB}$ and FC. Although studies of the effects of $G \times E$ to date have been mostly focused on the role of stressful environments in the expression of genetic predispositions for psychopathology, recently there is growing evidence that supportive environmental conditions play an interactive role for the development of adaptive behaviors (e.g., Taylor et al., 2010).

GE correlation refers to a situation where exposure to environments is in part determined by genotypes. For instance, adolescents with higher genetic propensities toward PB may evoke or create more positive and cohesive parentchild and sibling relationships by being willing to share or responding positively to the needs of parents or siblings. Thus, genetic influences on PB may be correlated with levels of FC, which would show up as a significant genetic correlation between $\mathrm{PB}$ and $\mathrm{FC}$ in the bivariate $\mathrm{G} \times \mathrm{E}$ model. In support of the presence of GE correlation for PB, PadillaWalker et al. (2013) showed that parents were somewhat more supportive toward children who displayed more PB within the family.

As most twin studies so far have been conducted in Western or Asian developed countries (Hur \& Craig, 2013), genetic and environmental etiologies of PB and family environment among African children living in very deprived environments remain largely unknown. In the present study, we investigated heritability of PB and FC among Nigerian adolescent twins attending public schools in Lagos State, Nigeria. Although evidence has been inconsistent, prior twin studies have shown that genetic influences on psychological traits, such as cognitive abilities are lower in disadvantaged environments than in average environments because poverty is a risk factor that may constrain genetic differences in cognitive abilities (e.g., Turkheimer et al., 2003). Chase-Lansdale et al. (1995) argued that poverty can make children pay less attention to the needs of others and produce harsh parent-child interactions that can be detrimental to the development of PB. In support of ChaseLansdale et al.'s notion, Bandy and Ottoni-Wilhelm (2012) found that compared to children in middle-class families, those who had lived in low-income families were lower in charitable giving and volunteering later.

As indicated by the rank (the 124th lowest country in the world) of the gross domestic product (GDP) per capita in 2015 (International Monetary Fund, 2015), most children in public schools in Nigeria live in an extremely impoverished environment. Furthermore, although family connectedness is very much valued among Nigerians, domestic violence is still widespread in Nigeria as it is in many parts in Africa (Oyediran \& Isiugo-Abanihe, 2005). As Nigeria is a patriarchal society, there is a cultural belief that it is acceptable to beat women and children to discipline them (Ntoimo \& Isiugo-Abanihe, 2014). Given these contextual risk factors, it is important to investigate whether genetic influences on PB and FC in Nigerian adolescents are substantially lower and shared environmental influences are significantly greater than those found in adolescents living in Western or Asian developed countries. Knowledge of the etiologies of $\mathrm{PB}$ and perceived FC, and the relationship between these among Nigerian adolescents, will have implications in determining effective policies on how to improve $\mathrm{PB}$ of children growing in extremely disadvantaged environments.

\section{Methods}

\section{Sample}

The sample was drawn from the ongoing Nigerian Twin and Sibling Registry (Hur et al., 2013). In total, 2,376 twin individuals (241 monozygotic male (MZM), 354 
TABLE 1

Sample Sizes and Descriptive Statistics for Age, Prosocial Behavior (PB) and Family Cohesion (FC), and Maximum Likelihood Twin Correlations ( $r$ ) for the Five Zygosity Groups and the Total Sample

\begin{tabular}{lllllll}
\hline & MZM & MZF & DZM & DZF & OSDZ & Total \\
\hline $\begin{array}{l}\text { N (individuals) } \\
\text { Age in years }\end{array}$ & 241 & 354 & 440 & 553 & 788 & 2376 \\
$\quad$ Mean (SD) & $14.9(1.7)$ & $14.5(1.7)$ & $14.9(1.7)$ & $14.8(1.6)$ & $14.6(1.8)$ & $14.7(1.7)$ \\
$\quad$ Range & $12-18$ & $12-18$ & $12-18$ & $12-18$ & $12-18$ & $12-18$ \\
PB & & $8.1(2.1)$ & $7.6(2.2)$ & $8.1(2.1)$ & $7.9(2.0)$ & $7.9(2.1)$ \\
$\quad$ Mean (SD) & $7.9(2.1)$ & $0.45(0.32-0.56)$ & $0.26(0.13-0.38)$ & $0.14(0.02-0.26)$ & $0.19(0.09-0.29)$ & \\
$\quad R$ & $0.28(0.11-0.44)$ & & & & $23.8(3.1)$ & $23.8(3.1)$ \\
FC & $23.7(3.2)$ & $23.8(3.0)$ & $23.6(3.1)$ & $24.0(3.0)$ & $0.15(0.05-0.25)$ & \\
$\quad$ Mean (SD) & $0.37(0.20-0.52)$ & $0.31(0.17-0.43)$ & $0.19(0.05-0.31)$ & $0.15(0.02-0.27)$ & $0.15)$ \\
$R$ &
\end{tabular}

Note: $M Z M=$ monozygotic male twins; MZF = monozygotic female twins; DZM = dizygotic male twins; DZF = dizygotic female twins; OSDZ = opposite-sex dizygotic twins.

monozygotic female (MZF), 440 dizygotic male (DZM), 553 dizygotic female (DZF), and 788 opposite-sex dizygotic (OSDZ) twins) aged from 12 to 18 years participated in the present study. These twins were recruited from 272 public junior secondary schools (JSS) and senior secondary schools (SSS) in Lagos State. In Nigeria, JSS covers a 3-year period for children aged about 12-14 years and SSS covers another 3-year period for children aged about 15-17 years. Our total sample consisted of 287 12-yearolds, 370 13-year-olds, 459 14-year-olds, 458 15-year-olds, 370 16-year-olds, 310 17-year-olds, and 122 18-year-olds. The mean age of the twins was 14.7 years with a standard deviation of 1.7 years (see Table 1 ).

We first obtained approvals to conduct this research from the Ministry of Education in Lagos State and the Health Research and Ethics Committee of the Lagos State University Teaching Hospital in Nigeria. With an approval, the Ministry of Education gave us a list of all public JSSs and SSSs in Lagos State. The school list included 639 schools registered as of 2011, along with the name and a telephone number of the principal of the school, the address of the school, and the number of students enrolled in the school. We attempted to contact schools with an enrolment size greater than 500 as we learned that the number of twins tended to vary depending on the enrolment size of the school. Unfortunately, the telephone numbers of many school principals in the list were outdated and schools were unreachable, although sometimes we were able to collect the correct telephone numbers from the nearest school principals. When we successfully reached the school principal by phone, we explained our research obtained an approval along with information about twins enrolled in the school, and scheduled the assessment of twins. Although most schools we contacted were very cooperative, we only visited schools when principals of the schools permitted us to carry out our study. Several school principals had to cancel their consent after we arrived in schools for various school circumstances. The final number of schools where we successfully gave assessments to twins was 272 (42.6\%). In each of the 272 schools, we administered questionnaires to twins in a library or a special classroom. Research assistants and school teachers were present in the testing room to monitor twins and give instructions to twins. During the testing session, a saliva sample was taken and analyzed to determine twins' zygosity. Eighteen microsatellite markers of DNA including amelogenin were analyzed to test zygosity of twins. A much larger number of DZ than MZ twins in the present sample likely reflects twin birth rates in Nigeria (MacGillivray, 1986). All twins and their school principals completed a written informed consent form. In addition, when parents were literate and available, teachers obtained verbal informed consent from parents on behalf of their twin children. The verbal and written informed consent forms were approved by the Health Research and Ethics Committee of Lagos State University Teaching Hospital. Our research has been conducted according to the ethical principles expressed in the Declaration of Helsinki.

\section{Measures}

PB scale: The PB scale was derived from the Strengths and Difficulties Questionnaire (SDQ; Goodman, 1997). The SDQ is a screening instrument for mental health problems for children and adolescents. It consists of five scales (Emotional Problems, Peer Problems, Hyperactivity/Inattention Problems, Conduct Problems, and PB), and has been translated into over 70 languages to be used for children and adolescents worldwide. Internal consistency, test-retest reliability, and validity of the scales have been shown to be satisfactory across different age groups and sexes (Stone et al., 2010). Recently, Stevanovic et al. (2015) showed that the PB scale of the SDQ consistently emerged from factor analysis of the SDQ items across several countries in Europe, South Asia, and Africa. The PB scale included five prosocial items regarding sharing, helping, and being kind and considerate of others. Twins were asked to rate themselves on a 3 -point Likert scale $(0=$ not true to $2=$ certainly true) for each item. Answers for the five prosocial items were summed to create a PB scale score. PB scores can range from 0 to 10 , where higher $\mathrm{PB}$ scores represent 


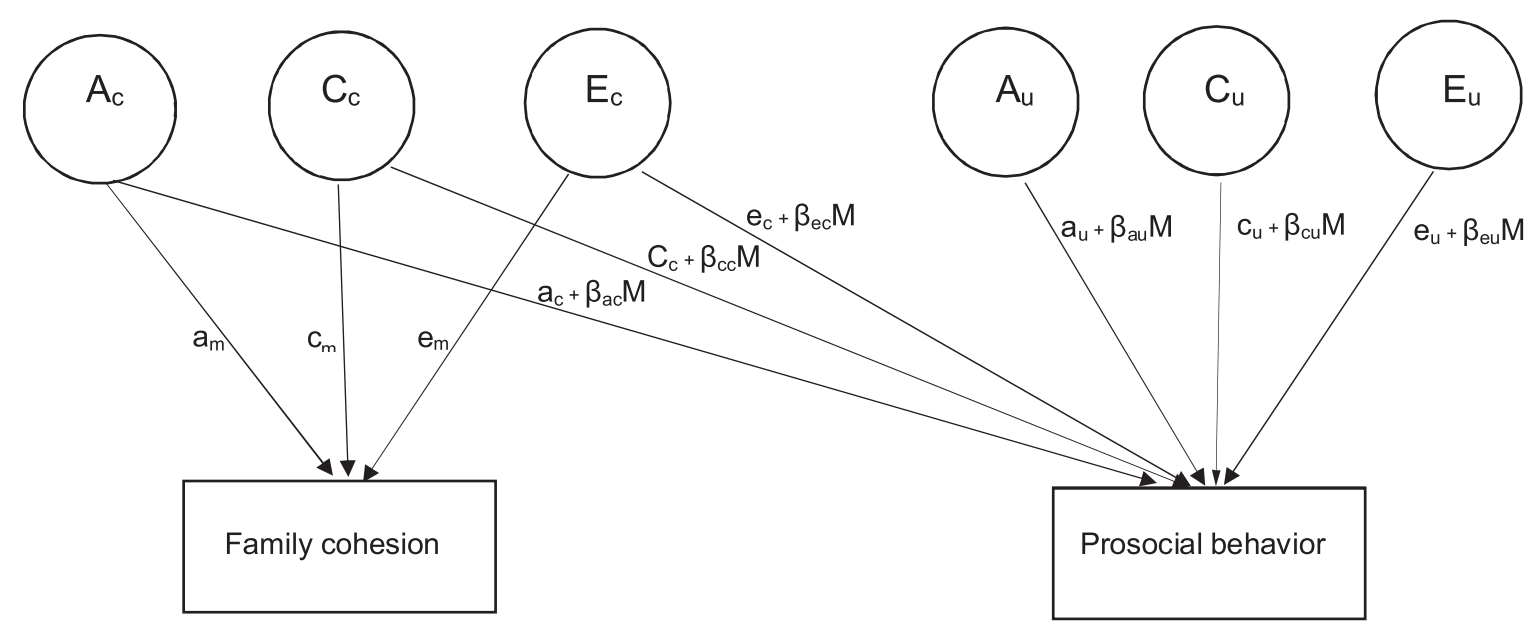

\section{FIGURE 1}

The bivariate $G \times E$ model: the paths $a_{m}, c_{m}$, and $e_{m}$ represent additive genetic, shared environmental, and non-shared environmental influences (respectively) on the moderator (M), family cohesion. The factors $A_{c}, C_{c}$, and $E_{c}$ represent additive genetic, shared environmental, and non-shared environmental influences, respectively, common in family cohesion and prosocial behavior. The factors $A_{U}, C_{U}$, and $E_{U}$ represent the additive genetic, shared, and non-shared environmental influences unique to prosocial behavior. Interactions with the moderator (e.g., $\beta_{\mathrm{ac}} \mathrm{M}$ ) are added to these common and unique genetic influences (and similar interactions are modeled for the shared and non-shared paths). See text for further details.

higher level of $\mathrm{PB}$. Cronbach alpha reliability of the five items was 0.63 in the present twin sample.

FC scale: The FC scale of the Family Adaptability and Cohesion Evaluation Scale III (FACES III; Olson, 1985) was used to measure cohesion of the family. FC consists of 10 items that assess the degree of separation or connectedness of family members.

According to Olson (1985), the FACES III is appropriate for children over 12 years old. Twins rated the 10 items of FC on a 3 -point Likert scale $(1=$ almost never to $3=$ almost always).

Answers for the 10 items were summed to create the FC score. The FC score can range from 10 to 30 . In generating the FC score, one missing item was allowed, where the score was prorated. Thus, higher FC scores represent higher family closeness and cohesion. Cronbach alpha reliability of the ten items was 0.62 in the present sample.

\section{Statistical Analysis}

An assumption in modeling twin data is that the phenotypic variance of a trait can be divided into three components: additive genetic, shared environment, and non-shared environment plus measurement error. The additive genetic component (A) includes the sum of the average effect of all alleles that influences a trait, which is set to be correlated at 1.0 and 0.5 for $\mathrm{MZ}$ and $\mathrm{DZ}$ twins, respectively. The shared environment component $(\mathrm{C})$ refers to the effects of environment common to twins that increase twin similarity. These effects are set at 1.0 for both $\mathrm{MZ}$ and $\mathrm{DZ}$ twins who are reared together, such as in the present twin sample. The non-shared environment plus measurement error (E) encompasses environmental effects unique to each member of a twin pair and error that decrease twin similarity. By definition, non-shared environmental effects are uncorrelated between two members of a twin pair.

Using Mx (Neale et al., 2003), we first fit a general sexlimitation model to the raw twin data to determine the estimates of A, C, and E for PB and FC separately. In the general sex-limitation model, we allowed sex differences in the estimates of $\mathrm{A}, \mathrm{C}$, and $\mathrm{E}$, and treated age as a covariate to control the main effect of age. Next, the bivariate $\mathrm{G} \times \mathrm{E}$ model (see Figure 1) incorporating perceived FC as a moderator was applied to the raw twin data. The bivariate $\mathrm{G} \times \mathrm{E}$ model is an extension of the bivariate Cholesky decomposition model (Neale \& Cardon, 1992). In Figure 1, the factors $A_{c}, C_{c}$, and $\mathrm{E}_{\mathrm{c}}$ represent additive genetic, shared environmental, and non-shared environmental influences common to $\mathrm{FC}$ and $P B$, respectively. The factors $A_{u}, C_{u}$, and $E_{u}$ represent additive genetic, and shared and non-shared environmental influences unique to $\mathrm{PB}$, respectively. In Figure 1, the effects of interaction with a moderator $(M: F C)$ were added to the main effects common to FC and PB $\left(\mathrm{a}_{\mathrm{c}}+\beta_{\mathrm{ac}} \mathrm{M}, \mathrm{c}_{\mathrm{c}}+\beta_{\mathrm{cc}} \mathrm{M}\right.$, $\left.\mathrm{e}_{\mathrm{c}}+\beta_{\mathrm{ec}} \mathrm{M}\right)$ and those unique to PB $\left(\mathrm{a}_{\mathrm{u}}+\beta_{\mathrm{au}} \mathrm{M}, \mathrm{c}_{\mathrm{u}}+\beta_{\mathrm{cu}} \mathrm{M}\right.$, $\left.\mathrm{e}_{\mathrm{u}}+\beta_{\mathrm{eu}} \mathrm{M}\right)$. In this way, the additive genetic $\left(\mathrm{a}_{\mathrm{c}}\right.$ and $\left.\mathrm{a}_{\mathrm{u}}\right)$, shared $\left(c_{c}\right.$ and $\left.c_{u}\right)$ and non-shared environmental $\left(e_{c}\right.$ and $e_{u}$ ) paths are extended to be a linear function of the moderator $M$. The regression weights ( $\beta$ terms) are unknown parameters to be estimated from the data and represent the extent to which the moderator alters the magnitudes of common and unique genetic and environmental influences, respectively. Thus, if the $\beta$ terms are significantly different from zero, there is evidence for a moderating effect.

It is important to note that GE correlation effects can resemble G×E in the model (Purcell, 2002; van der Sluis et al., 
2012). That is, as GE correlation is confounded with $\mathrm{G} \times \mathrm{E}$ in the model, false $\mathrm{G} \times \mathrm{E}$ effects may be spuriously detected that are actually due to common genes shared between the moderator (FC) and the outcome variable (PB). To control possible confounding role of GE correlation between the moderator and the outcome variable, the moderator (FC) is entered twice in the bivariate $\mathrm{G} \times \mathrm{E}$ model: once as a variable that is allowed to correlate with the outcome (PB) and once as a moderator. Additionally, one can estimate additive genetic, shared environmental, and non-shared environmental correlations between FC and $\mathrm{PB}$ (indexed by the covariance pathways between $\mathrm{FC}$ and $\mathrm{PB}$ in the bivariate $\mathrm{G} \times$ E model).

The maximum likelihood raw data option in $\mathrm{Mx}$ calculates twice the negative log-likelihood (2LL) of the data. As the difference in -2LL is chi-square distributed, when models are nested to each other, the likelihood ratio test (LRT) is used to evaluate alternative models. Significance of a parameter was tested by constraining the parameter to be zero and comparing the resulting model-fit statistics to that of the full model. When models are not nested to each other, Akaike's information criterion (AIC $=-2 \mathrm{LL}-2 d f$ ) for alternative models are compared. Models having lower AIC are considered more parsimonious and thus preferred (Akaike, 1987).

\section{Results}

\section{Descriptive Statistics and Twin Correlations}

Age was significantly correlated with $\mathrm{PB}$ but not with FC in the present sample. However, the size of correlation between PB and age was negligible $(r=0.06, p<.01)$ and appeared to have attained a statistical significance due to a large sample. Females had modestly but significantly higher scores of $\mathrm{PB}$ and FC than did males $(t=3.50, p<.01$ for $\mathrm{PB}$; $t=2.05, p<.05$ for FC). However, these means and variances of $\mathrm{PB}$ and $\mathrm{FC}$ were not significantly different across $\mathrm{MZ}$ and DZ twins. Maximum likelihood twin correlations for $\mathrm{FC}$ were 0.37 (95\% CI = 0.20, 0.52) for MZM, 0.31 (95\% $\mathrm{CI}=0.17,0.43)$ for $\mathrm{MZF}, 0.19(95 \% \mathrm{CI}=0.05,0.31)$ for DZM, 0.15 (95\% CI 0.02, 0.27) for DZF, and 0.15 (95\% CI $0.05,0.25)$ for OSDZ twins. Much higher MZ than DZ twin correlations in both sexes indicated the presence of additive genetic influences on FC. MZ and DZ twin correlations were lower than 1.0 in both sexes, which suggested the importance of non-shared environmental influences as well. MZ and DZ twin correlations were similar in males and females, showing that the magnitudes of additive genetic and non-shared environmental influences are similar in both sexes. OSDZ twin correlation for FC was not significantly lower than any of the same sex DZ twin correlations, which indicated that sex-specific genetic effects were not operating in FC. For PB, maximum likelihood twin correlations were $0.28(95 \% \mathrm{CI}=0.11,0.44)$ for $\mathrm{MZM}, 0.45$ $(95 \% \mathrm{CI}=0.32,0.56)$ for $\mathrm{MZF}, 0.26(95 \% \mathrm{CI}=0.13,0.38)$ for DZM, $0.14(95 \% \mathrm{CI}=0.02,0.26)$ for DZF, and $0.19(95 \%$ $\mathrm{CI}=0.09,0.29)$ for OSDZ twins. While MZ twin correlation was significantly higher than DZ twin correlation in females, they were similar in males. These patterns of twin correlations suggested possible sex differences in the magnitudes of additive genetic and non-shared environmental influences on PB. Consistent with FC, however, comparisons of OSDZ and same sex DZ twin correlations suggested little evidence for sex-specific genetic effects in PB. These observations made from twin correlations were tested using general sex-limitation model-fitting analysis below.

\section{General Sex-Limitation Model-Fitting Analysis}

Table 2 presents the results of the general sex-limitation model-fitting analyses for PB, and Table 3 for FC. Sexspecific genetic effects were not significant in $\mathrm{PB}$ (model 2 ). Model 3 removed additive genetic effects for males and shared environmental effects for females in PB, which led to a significant change in chi-square. These results suggested that additive genetic and shared environmental effects were not significantly different between the sexes in PB. Models 4 and 5 dropped shared environmental effects and additive genetic effects respectively for both sexes. The resulting chisquare change was significant in model 5 but not in model 4 , indicating that the AE model fit the data well for PB for both sexes. Model 6 further equated the A and E parameters across males and females, which yielded a non-significant change in chi-square. Thus, we chose model 6 as the bestfitting one for PB, where the AIC value was lowest among all of the models tested. Model 6 shows that additive genetic and non-shared environmental effects in $\mathrm{PB}$ were 0.38 (95\% $\mathrm{CI}=0.31,0.46)$ and $0.62(95 \% \mathrm{CI}=0.54,0.69)$, respectively in both sexes.

Model 2 in Table 3 indicates that sex-specific genetic effects were not significant in FC as well. Models 3 and 4 for FC showed that the AE model was much better than the CE model as the AIC value was lower in the former than in the latter model. Model 6 further constrained the parameters (A and $\mathrm{E}$ ) in model 3 to be equal across two sexes, whereas model 7 equated parameters (C and $\mathrm{E}$ ) in model 4 across two sexes. As model 6 had lower AIC value than did model 7 , and furthermore, the AIC value in model 6 was lowest among all models tested, we chose model 6 as the bestfitting one for FC. Model 6 yielded 0.33 (95\% CI $=0.24$, $0.40)$ for additive genetic effects and 0.67 (95\% CI $=0.60$, 0.76 ) for non-shared environmental effects for both sexes.

Overall, additive genetic and non-shared environmental effects found for FC and PB in the present sample were similar to the findings from previous twin studies of family environment (Hur \& Bouchard, 1995; Oliver et al., 2014) and PB (Hur, 2007; Hur \& Rushton, 2007; Knafo \& Plomin, 2006; Scourfield et al., 2004) in Western or Asian twin samples. As the results of the general sex-limitation model-fitting analysis showed no significant sex difference in either FC or PB, for further analysis we adjusted the scores of $\mathrm{PB}$ and $\mathrm{FC}$ for 
TABLE 2

Results of General Sex-Limitation Model-Fitting Analysis for Prosocial Behavior

Parameter estimates $(95 \% \mathrm{Cl})$

\begin{tabular}{|c|c|c|c|c|c|c|c|c|c|c|c|}
\hline \multirow[b]{2}{*}{ Model } & \multicolumn{5}{|c|}{ Goodness-of-fit statistics } & \multicolumn{3}{|c|}{ Male } & \multicolumn{3}{|c|}{ Female } \\
\hline & $-2 \mathrm{LL}$ & $d f$ & AIC & $\Delta \chi^{2}(\Delta d f)$ & $p$ & $\bar{A}$ & $C$ & $E$ & $\bar{A}$ & C & $E$ \\
\hline 1. $A_{m} \neq A_{f} C_{m} \neq C_{f}, E_{m} \neq E_{f}, r_{g} \neq 0.5$ & 11916.9 & 2753 & 6410.9 & & & $0.05[0.00,0.40]$ & $0.23[0.00,0.35]$ & $0.72[0.59,0.83]$ & $0.42[0.24,0.53]$ & $0.00[0.00,0.12]$ & $0.58[0.47,0.69]$ \\
\hline 2. $A_{m} \neq A_{f}, C_{m} \neq C_{f}, E_{m} \neq E_{f}, r_{g}=0.5$ & 11918.1 & 2754 & 6410.1 & $1.2(1)$ & .27 & $0.16[0.00,0.43]$ & $0.16[0.00,0.33]$ & $0.69[0.57,0.80]$ & $0.40[0.20,0.52]$ & $0.02[0.00,0.15]$ & $0.58[0.47,0.70]$ \\
\hline 3. $C_{m}, E_{m}, A_{f}, E_{f}, r_{g}=0.5$ & 11930.4 & 2756 & 6418.4 & $13.5(3)$ & .00 & - & $0.26[0.16,0.35]$ & $0.74[0.65,0.84]$ & $0.42[0.31,0.52]$ & - & $0.58[0.48,0.69]$ \\
\hline 4. $A_{m} \neq A_{f}, E_{m} \neq E_{f}, r_{g}=0.5$ & 11919.7 & 2756 & 6407.7 & $2.8(3)$ & .42 & $0.34[0.22,0.45]$ & - & $0.66[0.55,0.78]$ & $0.43[0.32,0.53]$ & - & $0.57[0.47,0.68]$ \\
\hline 5. $C_{m}^{\prime} \neq C_{f_{n}^{\prime \prime}}^{\prime} E_{m} \neq E_{f}, r_{g}=0.5$ & 11929.5 & 2756 & 6417.5 & $12.6(3)$ & .01 & - & $0.25[0.16,0.33]$ & $0.75[0.67,0.84]$ & - & $0.24[0.16,0.32]$ & $0.76[0.68,0.84]$ \\
\hline 6. $A_{m}=A_{f}, E_{m}=E_{f}, r_{g}=0.5$ & 11922.3 & 2758 & 6406.3 & $5.4(5)$ & .37 & $0.38[0.31,0.46]$ & - & $0.62[0.54,0.69]$ & $0.38[0.31,0.46]$ & - & $0.62[0.54,0.69$ \\
\hline
\end{tabular}

additive genetic correlation between opposite-sex DZ twins. Subscripts ' $m$ ' and ' $f$ ' denote male and female, respectively.

\section{TABLE 3}

Results of General Sex-Limitation Model-Fitting Analysis for Family Cohesion

\begin{tabular}{|c|c|c|c|c|c|c|c|c|c|c|c|}
\hline \multirow[b]{3}{*}{ Model } & \multirow{2}{*}{\multicolumn{5}{|c|}{ Goodness-of-fit statistics }} & \multicolumn{6}{|c|}{ Parameter estimates $(95 \% \mathrm{Cl})$} \\
\hline & & & & & & \multicolumn{3}{|c|}{ Male } & \multicolumn{3}{|c|}{ Female } \\
\hline & $-2 \mathrm{LL}$ & Df & $\mathrm{AIC}$ & $\Delta \chi^{2}(\Delta d f)$ & $p$ & $A$ & C & $\mathrm{E}$ & $\mathrm{A}$ & C & $\mathrm{E}$ \\
\hline 1. $A_{m} \neq A_{f}, C_{m} \neq C_{f}, E_{m} \neq E_{f}, r_{g} \neq 0.5$ & 13783.0 & 2697 & 8389.0 & & & $0.31[0.00,0.47]$ & $0.03[0.00,0.30]$ & $0.66[0.53,0.82]$ & $0.31[0.00,0.42]$ & $0.00[0.00,0.26]$ & $0.69[0.58,0.82]$ \\
\hline 2. $A_{m} \neq A_{f}, C_{m} \neq C_{f}, E_{m} \neq E_{f}, r_{g}=0.5$ & 13783.0 & 2698 & 8387.0 & $0.0(1)$ & .98 & $0.31[0.00,0.46]$ & $0.03[0.00,0.30]$ & $0.66[0.54,0.81]$ & $0.31[0.00,0.42]$ & $0.00[0.00,0.25]$ & $0.69[0.58,0.82]$ \\
\hline 3. $A_{m} \neq A_{f} E_{m} \neq E_{f}, r_{g}=0.5$ & 13783.1 & 2700 & 8383.1 & $0.0(3)$ & .99 & $0.34[0.21,0.46]$ & - & $0.66[0.54,0.79]$ & $0.31[0.20,0.42]$ & - & $0.69[0.58,0.80]$ \\
\hline 4. $C_{m} \neq C_{f}^{\prime}, E_{m} \neq E_{f}, r_{g}=0.5$ & 13789.9 & 2700 & 8389.9 & $6.8(3)$ & .08 & - & $0.22[0.12,0.31]$ & $0.78[0.69,0.88]$ & - & $0.20[0.11,0.28]$ & $0.80[0.72,0.89]$ \\
\hline 5. $E_{m} \neq E_{f}, r_{g}=0.5$ & 13838.1 & 2702 & 8434.1 & $55.1(5)$ & .00 & - & - & $1.00^{\mathrm{a}}$ & - & - & $1.00^{\mathrm{a}}$ \\
\hline 6. $A_{m}=A_{f}, E_{m}=E_{f}, r_{g}=0.5$ & 13784.1 & 2702 & 8380.1 & $1.1(6)$ & .95 & $0.33[0.24,0.40]$ & - & $0.67[0.60,0.76]$ & $0.33[0.24,0.40]$ & - & $0.67[0.60,0.76]$ \\
\hline 7. $C_{m}=C_{f}, E_{m}=E_{f}, r_{g}=0.5$ & 13790.9 & 2702 & 8386.9 & $7.9(5)$ & .16 & - & $0.21[0.15,0.26]$ & $0.79[0.74,0.85]$ & & $0.21[0.15,0.26]$ & $0.79[0.74,0.85]$ \\
\hline
\end{tabular}

Note: The best-fitting model for each variable is indicated in bold. $\mathrm{A}=$ additive genetic influence, $\mathrm{C}=$ shared environmental influence, $\mathrm{E}=$ non-shared environment plus measurement error. $-2 \mathrm{LL}=-2$ log-likelihood. $\mathrm{r}_{\mathrm{g}}=$ additive genetic correlation between opposite-sex DZ twins. Subscripts ' $m$ ' and ' $f$ ' denote male and female, respectively. 


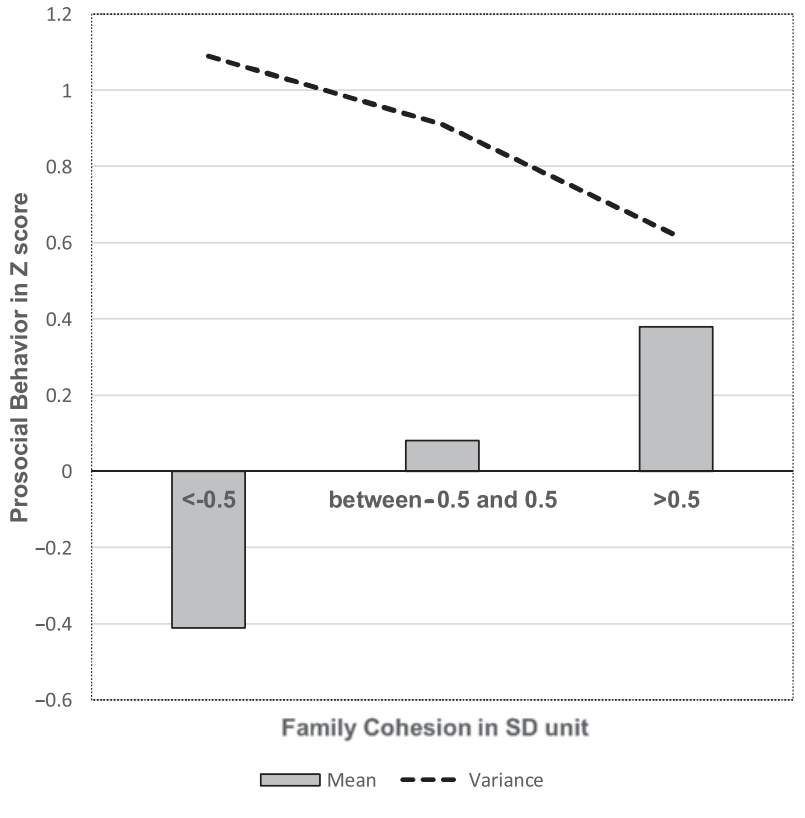

FIGURE 2

Means and variances of prosocial behavior as a function of family cohesion in SD unit. Scores were adjusted for sex and age and the residuals were standardized ( $z$ score).

sex and age by a regression method (McGue \& Bouchard, $1984)$ in a combined sample of males and females and standardized the residuals ( $z$ score) with a mean of zero and standard deviation of 1.0 .

\section{Bivariate $\mathbf{G} \times \mathbf{E}$ Model-Fitting Analysis}

Figure 2 shows that the mean level of PB increased progressively with increasing levels of FC. The phenotypic relationship between FC and PB was $0.36(p<.001)$. Note also in Figure 2 that the variance of $\mathrm{PB}$ declined with increasing levels of FC, suggesting that individual differences in $\mathrm{PB}$ are smaller in more cohesive families.

Table 4 presents the results of fitting the bivariate $\mathrm{G} \times \mathrm{E}$ models to the data. Consistent with twin correlations and the results of the general sex-limitation model-fitting analysis, removing all shared environmental paths from the full model resulted in a non-significant change in chi-square (model 2). When all moderation parameters were further removed from model 2 , a significant change in chi-square occurred (model 3), suggesting the presence of significant effects of moderation by FC in PB. While removing moderators for $A_{u}$ and $E_{u}$ from model 2 significantly worsened the model fit (model 5), removing moderators for $A_{c}$ and $E_{c}$ did not (model 4), indicating that moderation occurred on factors unique to $\mathrm{PB}$ rather than those common to $\mathrm{FC}$ and PB. From model 4, we further eliminated moderators for $\mathrm{A}_{\mathrm{u}}$ (model 6) and $\mathrm{E}_{\mathrm{u}}$ (model 7) individually. Although both models 6 and 7 were acceptable, the AIC value was much lower in model 6 than in model 7 and, furthermore, model 7 showed a borderline $p$ value. From these model compar- isons, we concluded that model 6 was the best-fitting, most parsimonious one. This model indicated that while genetic influences on PB were stable, non-shared environmental influences on $\mathrm{PB}$ varied significantly depending on the level of FC. Also of note, these environmental influences on PB moderated by FC were not the same as those overlapping environmental influences that underlie the association between FC and PB. In the best-fitting model, the genetic correlation between $\mathrm{PB}$ and $\mathrm{FC}$ was $0.59(95 \% \mathrm{CI}=0.54,0.63)$, whereas the non-shared environmental correlations varied from $0.18(95 \% \mathrm{CI}=0.11,0.25)$ at the lowest level of FC to $0.36(95 \% \mathrm{CI}=0.30,0.39)$ at the highest level of FC.

Figure 3 shows unstandardized additive genetic and non-shared environmental parameter estimates as a function of FC in the best-fitting model. In Figure 3, additive genetic variance for $\mathrm{PB}$ (solid line) was constant across all levels of FC, while non-shared environmental variance associated with $\mathrm{PB}$ (dashed line) decreased with increasing levels of FC. Thus, the declining total variance of PB (dotted line) with increasing levels of FC was due to a change in non-shared environmental variance rather than genetic variance; the non-shared environmental variance of $\mathrm{PB}$ was largest at the lowest level of $\mathrm{FC}$ and smallest at the highest level of FC. These results in the best-fitting model were in line with those found at the phenotypic level in Figure 2.

\section{Discussion}

The present Nigerian adolescent sample showed that while shared environmental effects were negligible, additive genetic and non-shared environmental factors significantly contributed to PB and FC. In spite of extreme poverty common in public school children in Lagos State, the estimates of additive genetic and non-shared environmental influences found in the best-fitting models were very similar to those reported in Western or Asian twin studies of PB and family environment (Hur \& Rushton, 2007; Kendler \& Baker, 2007; Oliver et al., 2014; Rowe, 1983; Scourfield et al., 2004). These results challenge the notion that genetic influences can be suppressed, while shared environmental factors can be more influential in psychological development of children in a disadvantaged environment (e.g., Turkheimer et al., 2003). The living conditions where our subjects lived were generally much worse compared to those of most twins in the lowest SES families who participated in Western or Asian twin studies. Thus, our findings suggest that an extremely disadvantaged environment itself may not be able to alter the magnitudes of genetic variations of $\mathrm{PB}$ and FC.

Consistent with the results from many Western and Asian twin studies of family environment, the present sample showed that non-shared rather than shared environmental factors accounted for most environmental variation of FC, suggesting that unique experiences of adolescents (e.g., observing interactions within families of their friends, 
TABLE 4

Goodness-of-Fit Statistics of the Bivariate GXE Models Testing for Moderation on Prosocial Behavior by Perceived Family Cohesion

\begin{tabular}{|c|c|c|c|c|c|c|}
\hline Model & Description & $-2 \mathrm{LL}$ & $d f$ & AIC & $\Delta \chi^{2}(\Delta d f)$ & $p$ \\
\hline 1 & Full moderation & 11529.0 & 4322 & 2885.0 & & \\
\hline 2 & $C_{m}=0, C_{c}+\beta_{c c} M=0, C_{u}+\beta_{c u} M=0$ & 11530.3 & 4327 & 2876.3 & $1.3(5)$ & .94 \\
\hline 3 & $\begin{aligned} \mathrm{C}_{\mathrm{m}}=0, \mathrm{C}_{\mathrm{c}}+\beta_{\mathrm{cc}} \mathrm{M} & =0, \mathrm{C}_{\mathrm{u}}+\beta_{\mathrm{cu}} \mathrm{M}=0, \beta \mathrm{ac} \mathrm{M}=0, \beta_{\mathrm{ec}} \mathrm{M}=0 \\
\beta_{\mathrm{au}} \mathrm{M}=0, \beta_{\mathrm{eu}} \mathrm{M} & =0\end{aligned}$ & 11589.5 & 4331 & 2927.5 & $60.5(9)$ & .00 \\
\hline 4 & $\mathrm{C}_{\mathrm{m}}=0, \mathrm{C}_{\mathrm{c}}+\beta_{\mathrm{cc}} \mathrm{M}=0, \mathrm{C}_{\mathrm{u}}+\beta_{\mathrm{cu}} \mathrm{M}=0, \beta_{\mathrm{ac}} \mathrm{M}=0, \beta_{\mathrm{ec}} \mathrm{M}=0$ & 11537.1 & 4329 & 2879.1 & $8.1(7)$ & .33 \\
\hline 5 & $\mathrm{C}_{\mathrm{m}}=0, \mathrm{C}_{\mathrm{c}}+\beta_{\mathrm{cc}} \mathrm{M}=0, \mathrm{C}_{\mathrm{u}}+\beta_{\mathrm{cu}} \mathrm{M}=0, \beta_{\mathrm{au}} \mathrm{M}=0, \beta_{\mathrm{eu}} \mathrm{M}=0$ & 11552.4 & 4329 & 2894.4 & $23.4(7)$ & .00 \\
\hline 6 & $\begin{array}{c}C_{m}=0, C_{c}+\beta_{c c} M=0, C_{u}+\beta_{c u} M=0, \beta_{a c} M=0, \beta_{e c} M=0, \\
\beta_{a u} M=0\end{array}$ & 11538.7 & 4330 & 2878.7 & $9.7(8)$ & .29 \\
\hline 7 & $\begin{array}{c}\mathrm{C}_{\mathrm{m}}=0, \mathrm{C}_{\mathrm{c}}+\beta_{\mathrm{cc}} \mathrm{M}=0, \mathrm{C}_{\mathrm{u}}+\beta_{\mathrm{cu}} \mathrm{M}=0, \beta_{\mathrm{ac}} \mathrm{M}=0, \beta_{\mathrm{ec}} \mathrm{M}=0 \\
\beta_{\mathrm{eu}} \mathrm{M}=0\end{array}$ & 11543.8 & 4330 & 2883.8 & $14.8(8)$ & .06 \\
\hline
\end{tabular}

Note: The best-fitting model is indicated in bold. $-2 L L=-2$ log-likelihood. The factors $A_{m}, C_{m}$, and $E_{m}$ represent additive genetic influences, shared environmental influences, and non-shared environmental influences (respectively) on the moderator (M), family cohesion. The factors $A_{c}, C_{c}$, and $E_{c}$ represent additive genetic influences, shared environmental influences, and non-shared environmental influences (respectively) shared between family cohesion and prosocial behavior. The factors $A_{U}, C_{U}$, and $E_{U}$ represent the genetic, shared, and non-shared environmental influences unique to prosocial behavior. Interactions with the moderator (e.g., $\beta_{\mathrm{ac}} \mathrm{M}$ ) are added to these common and unique genetic influences (and similar interactions are modeled for the shared and non-shared paths). See text for further details.

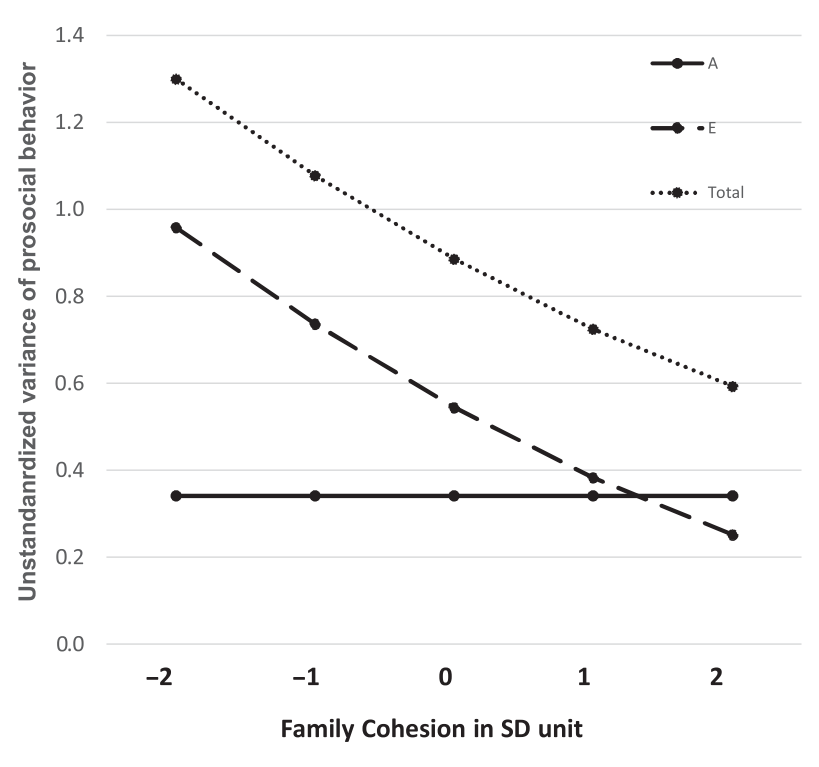

FIGURE 3

Unstandardized additive genetic (A), non-shared environmental, (E), and the total variance of prosocial behavior as a function of family cohesion in the best-fitting model.

having a close relationship to a teacher or a friend) are associated with individual differences in their perceptions of the cohesiveness of their own families. Our data failed to support the idea that individual differences in FC were associated with shared environmental variance, suggesting that aspects of the environment that are the same for both twins (e.g., family income, neighborhood characteristics, number of people in the home) are not explaining the variability in perceptions of family cohesiveness. In this way, it is important not to view FC as a static feature of the home environment that is the same for all people living in that home. Consistent with Kendler and Baker (2007), our findings suggest that FC among Nigerian adolescents may largely reflect the quality of the relationship to which each family mem- ber's genetically influenced interactional style contributes rather than the general family climate that family members share.

Although there were many prior studies demonstrating significant relationships between $\mathrm{FC}$ and $\mathrm{PB}$, to the best of our knowledge this is the first study to explain the etiology of this relationship in a genetically informative study. The bivariate $\mathrm{G} \times \mathrm{E}$ model revealed that $\mathrm{FC}$ modified the effect of non-shared environmental influences on $\mathrm{PB}(\mathrm{E} \times \mathrm{E}$ interaction), resulting in a decrease in variability of $\mathrm{PB}$. Specifically, the data showed an increase in mean level coupled with a decrease in total variance in $\mathrm{PB}$ across the range of FC values. Thus, adolescents in environments perceived to be very low in FC had an overall lower level of PB themselves, but there was a greater total variance (i.e., adolescents in less cohesive families were more disparate in their levels of $\mathrm{PB}$ ). This excess variance could be attributed to non-shared environmental variance, that is, unique experiences or factors (e.g., a particular life event, behavior of friends). In contrast, adolescents in environments perceived to be very high in FC had an overall higher level of $\mathrm{PB}$ and there was less variability (i.e., adolescents in more cohesive families were more similar in their levels of $\mathrm{PB}$ ). Non-shared environmental factors had little influence on variability in PB among these adolescents. It may be that a cohesive family relationship encourages adolescent children to associate with prosocial friends and maintain warm, close relationships with them. Thus, environmental experiences relevant to PB among cohesive families may be fairly consistent across individuals.

Although the present data emphasize the importance of non-shared environmental factors in explaining variance in $\mathrm{PB}$, especially in less cohesive environments, these data cannot identify which specific non-shared environmental variables are at work. Prior research suggests that 'peer' is an important environmental source for the development of PB (Barry \& Wentzel, 2006). In less cohesive environments, non-shared environmental factors such as parental differential treatment or conflicts with family members may 
influence adolescents' prosocial development by moderating peer relations and/or characteristics of friends they associate with. The magnitudes of non-shared environmental correlations between FC and PB found in the best-fitting model varied across levels of FC. However, they were generally low and likely to include correlated measurement error as the measures of PB and FC were both self-reported.

The genetic correlation between FC and PB was significant and constant across levels of FC. This association suggests that the relationship between FC and PB may in part be explained by an underlying GE correlation. That is, a genetic propensity for $\mathrm{PB}$ may be associated with an increased likelihood of creating cohesive family relationship. The significant genetic correlation also indicated that genes for $\mathrm{PB}$ may influence FC as well. Thus, identification of genes involved in PB may facilitate the search for genes for FC.

There are several limitations of the present study that need to be considered. First, the sample only consisted of Nigerian adolescent twins attending public schools in Lagos State. Prior studies (e.g., Chao, 2001) have shown that parenting styles are related to youth outcomes in different ways in various ethnic groups, thus, it remains to be seen whether or not the present findings extend to other ethnic groups. Second, English versions of the PB and FC scales were given to the participants in the present study. Although English is an official language used for education in Nigeria, many indigenous languages are still widely spoken by children at home (United States Library of Congress, 2008). Thus, somewhat lower internal consistency reliabilities of the two scales found in the present sample may reflect twins' developing skills in reading English. Finally, our measures of FC and PB are self-reported, which requires an assumption that both are veridical reports. However, a systematic review of self-report measures of the family environment scales has shown that the FC scale used in the present study is a suitable instrument for the evaluation of family functioning both in clinical and research settings (Hamilton \& Carr, 2016). Additionally, the mean (7.81) and standard deviation (2.2) of $\mathrm{PB}$ in our total sample were very close to those $($ mean $=8.1$ and $S D=2.0)$ found in another sample of randomly selected secondary school students in Ibadan in Nigeria (Stevanovic et al., 2015). These similarities in descriptive statistics of $\mathrm{PB}$ ensure validity of the responses of our participants.

To conclude, using this highly unique sample of Nigerian adolescents, we add two novel things in the literature of $\mathrm{PB}$ and family relationship. First, estimates of heritability and environmental influences on $\mathrm{PB}$ and FC among Nigerians are very similar to those found in Asian and Western twin samples. Second, FC alters adolescents' individual environmental experiences relevant to $\mathrm{PB}$, resulting in a decrease in variation of $\mathrm{PB}$, while increasing the mean level. Given the impact of positive PBs across many settings, our findings encourage the identification of meaningful experiences that contribute to FC that differ between siblings.

\section{Acknowledgments}

This research was supported by the Charles Darwin Research Institute (USA) and Ulster Institute for Social Research (UK) to the first author (YMH). Partial support was provided by NICHD grant P50 HD052120 (JT). We would like to thank twins who participated in this study and school teachers and principals in public schools in Lagos State, the staff members in the Ministry of Education in Lagos State, and many research assistants who kindly assisted this study. Special thanks are given to Human Pass, Korea who assisted us with twins' zygosity testing and Nick Martin for valuable comments to improve our original manuscript.

\section{References}

Akaike, H. (1987). Factor analysis and AIC. Psychometrika, 52, 317-332.

Bandy, R., \& Ottoni-Wilhelm, M. (2012). Family structure and income during the stages of childhood and subsequent prosocial behavior in young adulthood. Journal of Adolescence, 35, 1023-1034.

Barry, C. M., \& Wentzel, K. R. (2006). Friend influence on prosocial behavior: The role of motivational factors and friendship characteristics. Developmental Psychology, 42, 153-163.

Brownell, C. A. (2013). Early development of prosocial behavior: Current perspectives. Infancy, 18, 1-9.

Carlo, G., Mestre, M. V., McGinley, M. M., Tur-Porcar, A., Samper, P., \& Opal, D. (2014). The protective role of prosocial behaviors on antisocial behaviors: The mediating effects of deviant peer affiliation. Journal of Adolescence, 37, 359-366.

Chao, R. K. (2001). Extending research on the consequences of parenting style for Chinese Americans and European Americans. Child Development, 72, 1832-1843.

Chase-Lansdale, P. L., Wakschlag, L. S., \& Brooks-Gunn, J. (1995). A psychological perspective on the development of caring in children and youth: The role of the family. Journal of Adolescence, 18, 515-556.

DiLalla, L. F., Bersted, K., \& John, S. G. (2015). Evidence of reactive gene-environment correlation in preschoolers' prosocial play with unfamiliar peers. Developmental Psychology, 51, 1464-1475.

Eisenberg, N., \& Fabes, R. A. (1998). Prosocial development. In N. Eisenberg \& W. Damon (Eds.), Handbook of child development, Vol. 4: Social, emotional and personality development (5th ed., pp. 701-778). New York: Wiley.

Eisenberg, N., Fabes, R. A., \& Spinrad, T. (2006). Prosocial development. In N. Eisenberg, W. Damon \& R. M. Lerner (Series Eds.), Handbook of child psychology, Vol. 3. Social emotional and personality development (6th ed., pp. 646-718). Hoboken, NJ: Wiley.

Eisenberg, N., Guthrie, I. K., Murphy, B. C., Shepard, S. A., Cumberland, A., \& Carlo, G. (1999). Consistency and development of prosocial dispositions: A longitudinal study. Child Development, 70, 1360-1372. 
Goodman, R. (1997). The strengths and difficulties questionnaire: A research note. Journal of Child Psychology and Psychiatry, 38, 581-586.

Gregory, A. M., Light-Häusermann, J. H., Rijsdijk, F., \& Eley, T. C. (2009). Behavioral genetic analyses of prosocial behavior in adolescents. Developmental Science, 12, 165-174.

Hamilton, E., \& Carr, A. (2016). Systematic review of selfreport family assessment measures. Family Process, 55, 1630.

Hur, Y.-M. (2007). Effects of the chorion type on prosocial behavior in young South Korean twins. Twin Research and Human Genetics, 10, 773-777.

Hur, Y.-M., \& Bouchard, T. J. Jr. (1995). Genetic influences on perceptions of childhood family environment: A reared apart twin study. Child Development, 66, 330-345.

Hur, Y.-M., \& Craig, J. M. (2013). Twin registries worldwide: An important resource for scientific research. Twin Research and Human Genetics, 16, 1-12.

Hur, Y.-M., Kim, J. W., Chung, K. W., Shin, J. S., Jeong, H.-U., \& Auta, E. (2013). The Nigerian twin and sibling registry. Twin Research and Human Genetics, 16, 282-284.

Hur, Y.-M., \& Rushton, J. P. (2007). Genetic and environmental contributions to prosocial behaviour in 2- to 9-year-old South Korean twins. Biological Letters, 22, 664-666.

International Monetary Fund. (2015). World Economic Outlook Database, April 2015. Retrieved from https://www.imf. org/external/pubs/ft/weo/2015/01/weodata/index.aspx

Kendler, K. S., \& Baker, J. H. (2007). Genetic influences on measures of the environmental systematic review. Psychological Medicine, 37, 615-626.

Kerr, M. H., Beck, K., Shattuck, T. D., Kattar, C., \& Uriburu, D. (2003). Family involvement, problem and prosocial behavior outcomes of Latino Youth. American Journal of Health Behavior, 27, S55-S65.

Knafo, A., \& Plomin, R. (2006). Parental discipline and affection and children's prosocial behavior: Genetic and environmental links. Journal of Personality and Social Psychology, 90, 147-164.

MacGillivray, I. (1986). Epidemiology of twin pregnancy. Seminars in Perinatology, 10, 4-8.

McGue, M., \& Bouchard, T. J. Jr. (1984). Adjustment of twin data for the effects of age and sex. Behavior Genetics, 14, 325-343

Neale, M. C., Boker, S. M., \& Xie, G. (2003). Mx: Statistical modeling (6th ed.). Richmond, VA: Department of Psychiatry, Virginia Commonwealth University.

Neale, M. C., \& Cardon, L. R. (1992). Methodology for genetic studies of twins and families. London: Kluwer.

Ntoimo, L. F. C., \& Isiugo-Abanihe, U. (2014). Patriarchy and singlehood among women in Lagos, Nigeria. Journal of Family Issues, 35, 1980-2008.

Oliver, B. R., Trzaskowski, M., \& Plomin, R. (2014). Genetics of parenting: The power of the dark side. Developmental Psychology, 50, 1233-1240.

Olson, D. H. (1985). FACES III (Family adaptation and cohesion scales. St. Paul, MN: University of Minnesota.
Olson, D. H., \& Gorall, D. M. (2003). Circumplex model of marital and family systems. In F. Walsh (Ed.), Normal family processes (3rd ed., pp. 514-547). New York: Guilford.

Oyediran, K. A., \& Isiugo-Abanihe, U. (2005). Perceptions of Nigerian women on domestic violence: Evidence from 2003 Nigerian demographic and health survey. African Journal of Reproductive Health, 9, 38-53.

Padilla-Walker, L. M., Carlo, G., Christensen, K. J., \& Yorgason, J. B. (2013). Bidirectional relations between authoritative parenting and adolescents' prosocial behaviors. Journal of Research on Adolescence, 22, 400-408.

Plomin, R., DeFries, J. C., \& Loehlin, J. C. (1977). Genotypeenvironment interaction and correlation in the analysis of human behavior. Psychological Bulletin, 84, 309-322.

Purcell, S. (2002). Variance components models for geneenvironment interaction in twin analysis. Twin Research, 5, $554-571$

Rowe, D. C. (1983). A biometrical analysis of perceptions of family environment: A study of twin and singleton sibling kinships. Child Development, 54, 416-423.

Scourfield, J., John, B., Martin, N., \& McGuffin, P. (2004). The development of prosocial behavior in children and adolescents: A twin study. Journal of Child Psychology and Psychiatry, 45, 927-935.

Sijtsema, J. J., Nederhof, E., Veenstra, R., Ormel, J., Oldehinkel, A. J., \& Ellis, B. J. (2013). Effects of family cohesion and heart rate reactivity on aggressive/rule-breaking behavior and prosocial behavior in adolescence: The tracking adolescents' individual lives survey study. Development and Psychopathology, 25, 699-712.

Stevanovic, D., Urbán, R., Atilola, O., Vostanis, P., Singh Balhara, Y. P., Avicenna, M., ... Petrov, P. (2015). Does the strengths and difficulties questionnaire - self report yield invariant measurements across different nations? data from the international child mental health study group. Epidemiology and Psychiatric Sciences, 24, 323-334.

Stone, L. L., Otten, R., Engels, R. C. M. E., Vermulst, A. A., \& Janssens, J. M. A. M. (2010). Psychometric properties of the parent and teacher versions of the strengths and difficulties questionnaire for 4- to 12-year-olds: A review. Clinical Child and Family Psychology Review, 13, 254274.

Taylor, J., Roehrig, A. D., Soden-Hensler, B., Connor, C. M., $\&$ Schatschneider, C. (2010). Teacher quality moderates the genetic effects on early reading. Science, 328, 512-514.

Turkheimer, E., Haley, A., Waldron, M., D'Onofrio, B., \& Gottesman, I. I. (2003). Socioeconomic status modifies heritability of IQ in young children. Psychological Science, 14, 623-628.

United States Library of Congress. (2008). Country profile - Nigeria. Retrieved from https://www.loc.gov/rr/frd/cs/ profiles/Nigeria.pdf

van der Sluis, S., Posthuma, D., \& Dolan, C. V. (2012). A note on false positives and power in $\mathrm{G} \times \mathrm{E}$ modelling of twin data. Behavior Genetics, 42, 170-186. 